\title{
Case Studies And How They Are Used
}

\author{
John Parkinson, York University, Canada
}

\begin{abstract}
Although case studies are widely used there are different opinions on what constitutes a case, and what the educational objectives are. In summarizing some of the theory underlying the writing and use of cases [e.g. Eisenbeis, 1994, Erskine et al, 1998, Gilbertson \& Gilbertson, 1995], we come to the conclusion that the choice of appropriate cases is dependent on the contextual factors, in particular whether the case is to be used to enable student learning, or, alternatively, if it is to be used to assess student learning.
\end{abstract}

Keywords: Case study theory; Case study use; Case difficulty cube.

\section{INTRODUCTION}

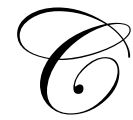

ases are widely used in business education, though their use is not universal. A useful way of characterizing this is that they may be fundamental to the educational process (e.g. the Harvard Business School model) they may be proscribed (several schools do not use cases as a matter of policy) or that they may be used in some situations, but not others (most business schools would be included here).

One reason for using cases is that they enable higher-level learning: a taxonomy of educational objectives has been proposed [Bloom et al,1956 and Andrews \& Krathwol, 2001] running from the lowest levels (knowledge acquisition) through comprehension, application, analysis, synthesis, and evaluation (the highest level): whereas traditional lecture/demonstration based teaching can only aspire to the lower levels, it is suggested that the case approach has the capability to deal with the entire range: "Cases afford the opportunity to address all seven levels of Bloom's Taxonomy, provided that is the instructor's intent" [Erskine et al, 1998, p. 49]: this idea is neatly captured by the title of one of the seminal articles on cases "Because wisdom can't be told" [Gragg, 1954]. Within the debate about where cases are best used is a debate about what constitutes a case. In this paper we shall examine some of the features of case studies (or, if you take a particular perspective, features of things that are not cases).

\section{REAL VERSUS FICTIONAL}

On the one hand, there are those who insist that a case is based on reality. "Cases presented for discussion should depict events that actually occurred" [Naumes, 1989]. The type of case used at Harvard, for example is always a "real" case. The benefit of reality is that (pace the ability of the case writer to correctly capture the case facts) it is unarguably something a manager actually had to deal with, and is therefore implicitly relevant. It has an externally identified integrity. In certain sensitive situations the organization may be changed or disguised, but even in those situations there is an underlying reality that gives the case credibility.

One downside of the insistence on reality is that there may be no case written that covers the particular topic the instructor wants to address: in the writers own area, for example, I know of no reality-based case that deals with the issue of the use of first-in-first-out versus weighted average inventory systems in process costing.

A further feature of a real case is whether or not it has received a "release" (in other words an approval) from the organization, as would be insisted upon by Chrisman [1990] and by Naumes [1989]. This is strongly contested by Sharplin [1990]. Clearly a release adds to the credibility of a case, but some cases are prepared about real organization without the organization itself being part of the case writing process (e.g. where all the necessary information is in the public domain): here a release would seem redundant. The issue becomes even more 
problematical where the case confronts the organization: here a release may be impossible to obtain, whatever the veracity of the case information.

The alternative extreme is an invented or "armchair" case. This will almost always have the benefit of directly addressing a particular topic, and can be nuanced to bring out particular aspects of a topic. One of the justifications for armchair cases is that they may be compilations of discrete vignettes, each from a real situation, but not all found in the same place. In other situations the entire case is fictional. Armchair cases may be justified by their usefulness. For example one of the most widely used cases in transfer pricing is Birch Paper [Anthony, Dearden \& Govindarajan, 2007, p. 254]: according to the author it is completely contrived (personal communication: Bill Rotch). Its wide use could only be because it is educationally effective.

\section{LONG VERSUS SHORT}

The Harvard type case is always long, with 20 plus pages being common. If the case writer is dealing with a real situation, and familiarization with the case environment and the background situation is deemed necessary, length will be necessary.

Chrisman [1990] includes the following expectation of the content of a case:

"Although the types of information will vary depending on the focus of the case, as a general rule a good case will contain as much information as possible about the situation facing the company. I will include data on all or most of the organization's main competitors, its suppliers, its customers and so on. Cases should also provide at least a modest amount of information on the general economic, social, legal and political environment of the organization. Demographic data and information on the local environment should also be provided where applicable.

Furthermore the case should describe, to the greatest extent possible, the strategy, objectives, finances and internal operations of the company. The products or services the organization offers and the markets it serves are absolutely essential. The functional operations and policies of the organization should be comprehensively described as well. It is also necessary to describe the unique advantages or disadvantages the organization possesses in each functional area so the reader will understand what the organization can and can not do to deal with the problems it faces.

In addition, the case should provide background data on the organization and its managers and personnel. If possible, it is useful to bring the individuals in the case to "life" so to speak, by providing hints on their personalities and problems. Direct quotes and conversations are especially useful in this respect. Such devices give the case a special flavor and helps the reader better relate to the situation" [op cit p.6].

With this list as a guideline, a short case becomes a manifest impossibility. Indeed, any organization that was able to readily provide the case writer with all this information is probably not facing any meaningful decision point, other than dealing with an embarrassing information overload.

Many users find a long case so unwieldy that it interferes with the educational process. Rather than have the student spend time making themselves familiar with the case situation, it may be felt that the time is better spent dealing with the educational topics. For them a short case is more suitable.

Length is a part of the "Presentation" dimension of the "Case Difficulty Cube" [Erskine, 1998]. Implicit in this is that instructors should choose a particular case presentation, including length, to fit their educational objectives.

\section{COMPLETE VERSUS INCOMPLETE}

A case may contain all the information necessary for an effective analysis. Conversely a case may deliberately omit certain points, with the expectation that the student will recognize what is necessary but not supplied, and react accordingly (e.g. look up missing data; make appropriate assumptions etc.) Cases may also 
contain redundancies. It becomes the student task to identify these and exclude them from the analysis. The minimally complete case, the incomplete case and the case with redundancies each test different skills. Completeness is another part of the "Presentation" dimension of the "Case Difficulty Cube" [op. cit.]

\section{COMPLEX VERSUS STRAIGHTFORWARD}

Complexity is a second dimension of the "Case Difficulty Cube" [op. cit.] The simplest case will deal with a single, easily identifiable issue. In a more complex case the issue will be less easily identified or there will be multiple issues or the issues themselves may depend on relatively complex concepts. In the most complex cases there will be multiple difficult issues, none of which is easy to identify and the issues may interact with each other.

Part of this is under the control of the case writer. A clearly directed case will eliminate any lack of clarity. The total absence of direction leaves problem identification as a key aspect of the case's educational objectives. Parkinson \& Taggar [2006] investigated personalities associated with successful case analysis. Overall, students with higher GPAs tended to do better on cases than those with lower GPAs, which was hardly a surprise. However, creative types were relatively good at problem identification, while the conscientious types were relatively good at problem analysis. This is an issue that should not be ignored. If this difference exists, then setting students a case study becomes a joint test of their mastery of the case, and the students' personality. Furthermore, the type of case, particularly the difference between a directed case and an undirected case becomes a critical differentiating feature in respect of their probability of success.

\section{DECISION FOCUS}

The third dimension of the "Case Difficulty Cube" [op. cit.] is that of a decision focus. Chrisman [1987]; Naumes [1989] and Campbell \& Lewis [1991] all say that a decision focus is an essential aspect of any case. The easiest cases require the evaluation of a decision that has already been taken; more difficult cases require a decision in respect of a directed issue; the most difficult cases require the student to identify the decision and then resolve it. By implication, Erskine is accepting that cases which do not require the student to make a decision are still cases. The perspective that cases without a specific decision focus are still cases is also apparent from the writings of Knechel [1992] and Sharplin [1990].

\section{EDUCATIONAL PURPOSE}

It is a fact that the case study method is widely used in business education, and that is reflected in the lively discussion of the nature of cases and the case teaching process. Much of the writing about cases focuses on the classroom process, and in particular the ways that students should approach the case for the classroom situation [Cambell \& Lewis, 1991; Mauffette-Leenders et al, 1999]. The assumption here is that it is the educational process in the classroom that is the essential aspect of using case studies.

Reality at the time of this writing, however, is that cases are also used for assessing outcomes [Michlitsch $\&$ Sidle, 2002; Parkinson,1999]. They are used during courses (e.g. a report submitted for all or part of a term-work grade; a participation mark based on contribution to case discussion); they are used at the end of courses (as all or part of a final exam); they are used by outside agencies (e.g. the comprehensive exams of the Canadian Institute of Chartered Accountants); and they are used by organizations as part of assessment centers when applicants receive a series of standardized assessment procedures to evaluate candidates for selection, classification, and promotion.

If cases are to be used for assessing outcomes, then a discussion of the theoretical aspects of that assessment process is justified and desirable. Sadly the literature is sparse in this area. Erskine et al, [1998] refer to the identification of issues and issue analysis as the first two steps in preparing a case response. These phases are similar to those of creative problem solving, which is considered by many to be the cornerstone of organizational competitive advantage [Amabile, 1996; Devanna \& Tichy, 1990; Shalley, 1995]. 
Specific articulations of the creative problem solving process have been published for different applications (for instance, the five-step creative sequence for advertising [Young, 1974]. Whatever the specific articulation, all models essentially break creative problem solving into two distinct stages [Baer, 1993]: A "divergent phase" or idea generation phase (brainstorming), and a "convergent phase" where the ideas generated are evaluated and analyzed and an optimum solution selected. The final quality of the solutions appears to be dependent on the quality of execution of each of these two-chained phases. Parkinson [1999] surveyed the ways case assessment was carried out, concluding that assessment differed as a function of instructor, of subject area and of level within subject area. Analysis was weighted highest in the assessment process, followed by problem identification, but both were the dominant components of all assessment schemes.

\section{METHOD OF ANALYSIS} Harvard.

Gilbertson \& Gilbertson [1995] identify two main approaches to the process of case analysis: Western and

The Western Ontario University analytic approach provides a detailed structure consisting of:

- $\quad$ Read the case;

- $\quad$ Identify the problem(s);

- $\quad$ Summarize the information;

- $\quad$ Analyze the information;

- $\quad$ Re-consider the problem(s);

- $\quad$ Develop alternatives to deal with the problems(s);

- $\quad$ Assess the advantages and disadvantages of each alternative;

- $\quad$ Evaluate the alternatives;

- $\quad$ Recommend an alternative;

- $\quad$ Recommend a strategy for implementing the chosen alternative;

- $\quad$ Create a formal presentation of the whole process.

The "Harvard" approach, does not dictate a specific chain of actions, but relies more on a Socratic process of discovery through question and answer.

It is possible (in come instances probable) that either approach could result in the same decision. This is a likely to be true for simple cases. More complex cases or those that are more "value-driven" might well result in the two approaches yielding different decisions. What seems obvious, though, is that the Western approach is very well suited to dealing with a hand-in case that has to be assessed separately from the case process itself, while the Harvard approach is well suited to the classroom, and would be much more challenging to assess with any degree of objectivity.

McKenna [1999] used these two models to investigate the analysis of live cases by MBA students. The students using the Western model adopted a role as external experts; the students using the Harvard model adopted the role of "facilitators of learning when working with the client". He found the Harvard approach to be more effective in developing organizational learning.

\section{THE ROLE OF THE INSTRUCTOR}

Eisenbeis [1994] shows how the instructor can adopt any of four perspectives when dealing with a case in the classroom situation:

The facilitator has a minimalist level of interaction with the process, leaving the students to develop their analysis through their own efforts. Where it is successful it will lead to the greatest levels of creative thinking and learning. 
The coach has a higher level of interaction, through questioning, probing and clarifying. The students are still responsible for identifying problems and uncovering cause and effect relations. Where it is successful it will lead to relatively high development of analytical and reasoning skills.

The quarterback is vocally very involved in the class discussion and guides the students in appropriate directions to ensure their treading the correct path. Students will gain an appreciation of case approach, but have less opportunity to make a deeply meaningful contribution to the process: development of analytical and reasoning skills is considerably reduced.

The demonstrator spends most of his time showing the correct solution and how it was arrived at, with only occasional requests for input from the students. Creative thinking will not be highly stimulated.

Eisenbeis's own preference is to be a facilitator: this is in keeping with the objective of wanting to stimulate the highest type of learning. The low level of involvement, however, requires careful attention if it is not to descend into an abdication of the role of instructor.

Classroom experience tells us that most students want cases to be demonstrated to them under the mistaken supposition that being told how to do one case will show them how another case should be done. The writer's own preference is to be a coach, but to feel an almost irresistible pressure from students to become a quarterback.

As a further addition to the instructor role, in a world where not all teaching is done in a classroom, we would have to ask how internet instructors deal with their role in case analysis.

\section{SUMMARY}

Case studies are a feature of much business education, and they are very appropriate for that purpose [Erskine et al, 1998]. There are different expectations of what constitutes a legitimate case, and what fails to measure up to being a case. As is pointed out by Dooley \& Skinner [1977] the case method covers such a wide disparity of actual practices that discussion is inherently problematical.

Clearly the type of case that is: reality-based; long; incomplete; containing redundancies; multi-problem and undirected has its place, at the peak of the educational mountain. However, there is a role for the type of case that is all or some of: fictional; short; minimally complete; single-issue and clearly directed where the educational objectives are more circumscribed. This should be a situationally specific issue: instructors should take pains to ensure that the type of case selected is a good match with the students, the learning objectives and the contextual factors that underlie their use.

\section{AUTHOR INFORMATION}

John Parkinson is Professor of Accounting \& Finance and Director of the Atkinson School of Administrative Studies at York University. He graduated with a $\mathrm{PhD}$ in finance from Bradford University Management Centre in England, and he holds professional memberships as Fellow of the Institute of Chartered Accountants in England \& Wales and Fellow of the Chartered Institute of Management Accountants.

His main research interests are the application of process costing in modern manufacturing companies, and the interaction of personality measurement with accounting research and practice and the development and use of case studies.

\section{REFERENCES}

1. $\quad$ Amabile, T.M., 1996, Creativity in Context. Boulder, Co: Westview Press, Inc.

2. Andrews, L. W. \& D. Krathwohl, 2001, A Taxonomy for Learning, Teaching and Assessing: a Revision of Bloom's Taxonomy of Educational Objectives. New York: Longman 
3. Anthony, R.N., \& V. Govindarajan, 2007, Birch Paper, Management Control Systems, $12^{\text {th }}$ ed, McGrawHill Irwin, p. 254

4. Baer, J. (1993). Creativity and Divergent Thinking: A Task Specific Approach. Hillsdale, NJ: Lawrence Earlbaum Associates.

5. $\quad$ Bloom, B. S., Englehart, M. D., Furst, G. J., Hill, W. H., \& Krathwohl, D. R. (1956). Taxonomy of Educational Objectives: the Cognitive Domain. New York: David Mckay Co.

6. Cambell, J.E. \& W.F. Lewis, 1999, Using Cases in Accounting Classes, Issues in Accounting Education, Vol. 6, \#2, 276-283.

7. Chrisman, J.J, 1990, Writing Publishable Cases: Some Guidelines, Case Research Journal, Spring, 1990, pp. 4-9.

8. Devanna, M.A. \& N. Tichy, 1990, Creating the Competitive Organization of the 21st Century: The Boundaryless Corporation. Human Resource Management, 29, 445-471.

9. Dooley, A.R. \& W.Skinner, 1977, Casing Casemethod Methods, The Academy of Management Review, Vol.2, \#2, pp. 277-289.

10. Eisenbeis, 1994, Using the Facilitator Role in Case Teaching: a Personal Perspective, Case Research Journal, Vol 14, \#2, pp.121-133.

11. Erskine, J.A, M.R. Leenders \& L.A. Mauffette-Leenders, 1998, Teaching with Cases, University of Western Ontario, London, ON.

12. Gilbertson, D. \& D. Gilbertson, 1995, Innovation \& Management: New Zealand Case Studies, Dunmore Press, Palmerston North.

13. Gragg, C. I. 1954, Because Wisdom Can't be Told, in M. P. McNair (Ed), The Case Method at Harvard Business School. New York: McGraw-Hill.

14. Knechel, W.R., 1992, Using the Case Method in Accounting Instruction, Issues in Accounting Education, Vol. 7, \#2, pp. 205-217.

15. Mauffette-Leenders, L.A., J.A. Erskine \& M.R. Leenders, Learning with Cases, 1997, University of Western Ontario, London, ON.

16. McKenna, S., 1999, Organizational Learning: Live Case Studies and the Consulting Process, Organizational Learning, Vol 5, \# 4, pp. 125-135.

17. Mitchlistch, J. F., \& M. W. Sidle, 2002, Assessing student learning outcomes: a comparative study of techniques used in business school disciplines. Journal of Education for Business, 77, 125 - 130.

18. Naumes, W., 1989, Case Writing, Professional Development and Publishing Standards: Guidelines for the Case Research Journal, Case Research Journal, Vol. 23, \#s 1\&2, pp. 145-150.

19. Parkinson, J.M., 1999 Differences in the Assessment of Case Studies, Paper presented at the 16th International Conference on Case Method \& Case Application, Caceres, Spain.

20. Parkinson, J.M. \& S. Taggar 2006, Intelligence, Personality and Performance on Case Studies, Journal of Business \& Psychology, published online: 7 February 2006.

21. Shalley, C.E. 1995, Effects of Coaction, Expected Evaluation, and Goal Setting on Creativity and Productivity. Academy of Management Journal, Vol. 38, pp. 483-503.

22. Sharplin, A., 1990, Towards Reasonable Standards for Publishable Cases, Case Research Journal, Spring, pp. 10-16

23. Young, J.W. 1974, A Technique for Producing Ideas. Chicago: Crain Books. 